\title{
CONGENITAL COMPLETE HEART BLOCK
}

\author{
BY \\ JOHN THOMSON, M.D., D.C.H., D.P.H. \\ (From the Department of Child Life and Health, University of Edinburgh)
}

Congenital complete heart block is an uncommon condition. The two cases now recorded are of particular interest because they were diagnosed before birth. The diagnosis was confirmed postnatally by electrocardiogram.

Case 1. H., a male infant weighing $7 \mathrm{lb}$., was born on February 9, 1943, the first child of a twentyfive-year-old mother. During the mother's pregnancy the foetal heart sounds were never heard. Foetal movements were present from four-and-ahalf months. Following rupture of the membranes seven hours twenty minutes before delivery, the foetal heart sounds became audible. The very slow rate was noted. It was regular, and the provisional diagnosis of complete heart block was suggested. At delivery the condition of the infant was good: there was no cyanosis. Auscultation of the heart disclosed no murmurs. The ventricular rate fluctuated from time to time and varied between sixty and seventy-six per minute. The infant was breast fed and made normal progress.

When five-and-a-half days old, two electrocardiograms and a skiagram were made. The first electrocardiogram showed an auricular rate of 176 per minute, a ventricular rate of 60 per minute, a constant $P-R$ interval of $\mathbf{0 . 2}$ second, $P$ waves upright in all leads, and the right axis deviation which is normally associated with the newborn infant.
It suggested a $3: 1$ heart block. The second electrocardiogram showed a complete heart block. The auricular rate was constant at 188 per minute, while the ventricular rate varied between 60 and 71 per minute. The $P-R$ interval varied between $0 \cdot 1$ and 0.28 second. The skiagram disclosed a globular heart shadow. The outline of the right auricle extended well out to the right. The supracardiac shadow was abnormally wide. The whole appearance suggested some structural cardiac abnormality, in all probability a degree of septal defect.

At the age of seventeen weeks a faint murmur could be heard. It was not well defined but could be heard best in the mitral region. An electrocardiogram and a skiagram were taken at this time. The former showed a persistence of the complete heart block. The auricular rate was 150 per minute and the ventricular rate approximately 52 per minute. The skiagram showed the cardiac outline to be unchanged.

Since the infant was born the ventricular rate has shown a downward trend. This is illustrated in the following table:

$\begin{array}{cc}\text { Age in days } & \text { Ventricular rate per minute } \\ \text { Birth } & 60-76 \\ 5 & 60-71 \\ 31 & 84 \\ 38 & 60 \\ 73 & 56 \\ 124 & 52\end{array}$

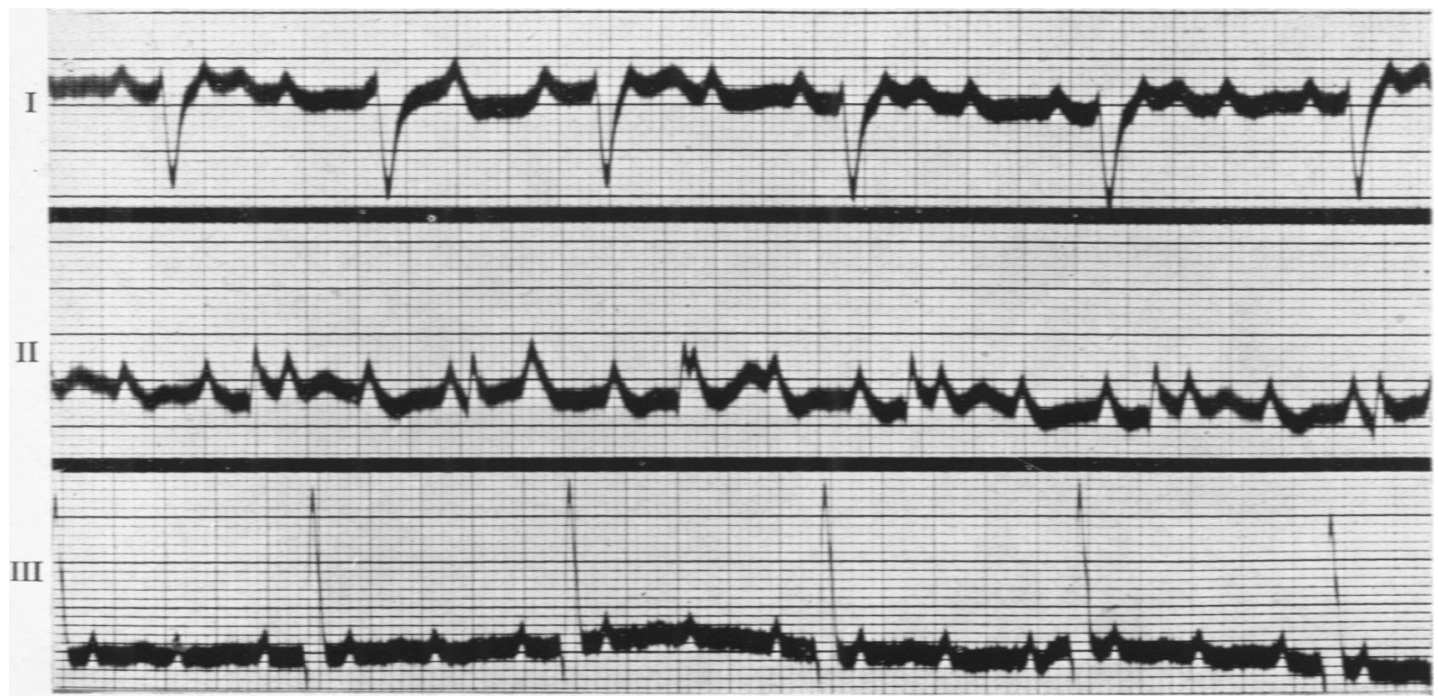

FIG. 1.-Case 1. Electrocardiogram at age $5 \frac{1}{2}$ days 


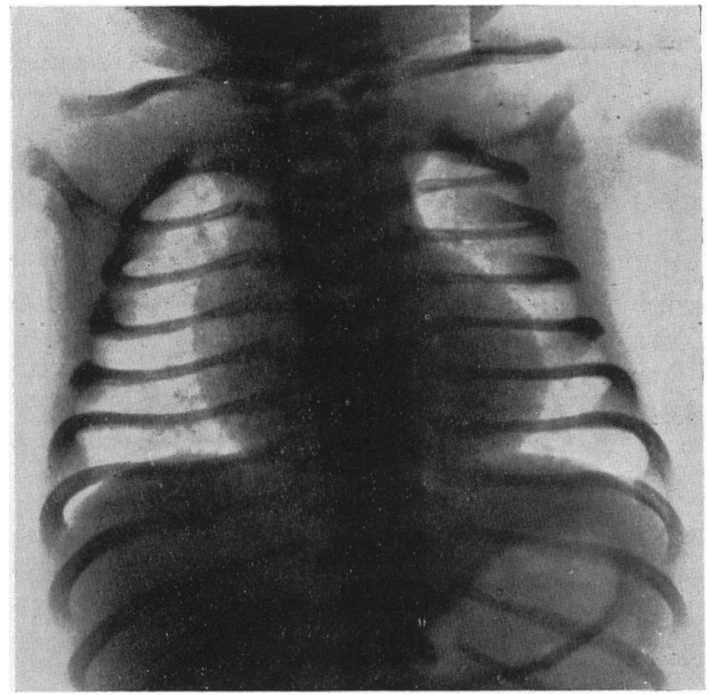

FIG. 2.-Case 1. Skiagram at age $5 \frac{1}{2}$ days

Cyanosis has been observed on only one occasion. It occurred during a fit of crying when the infant was 38 days old, and only amounted to a faint tinge round the mouth and eyes. The infant is now twenty-three weeks old and is clinically well.

Because of the occurrence of complete heart block in the infant, the mother's electrocardiogram was taken. This disclosed a bundle branch block, type IIa (Wilson). It is a matter for speculation whether this cardiac condition in the mother has had any relation to the occurrence of heart block in the infant. The mother, who had had diphtheria in childhood, is healthy at present. Several blood relatives of the mother, including her mother, have been examined but no other cases of heart block have been found.

Case 2. J., a female infant weighing $6 \mathrm{lb} .5 \frac{1}{4} \mathrm{oz}$., born on March 28, 1943, the first child of a thirtytwo-year-old mother whose Wassermann reaction was negative. Movements were felt at about five months. No foetal heart sounds were heard until about six-and-a-half months. They were then noted to be slow. At four-and-a-half weeks before delivery the rate was forty-five per minute and at four weeks before delivery it was forty-eight per minute. On the day before delivery the foetal heart was not heard. During the labour which lasted approximately twenty-two hours, it became audible but it was irregular. Rupture of the membranes disclosed that the liquor amnii was mixed with meconium. The labour was thereupon terminated by a forceps delivery. The infant was found to be in fairly good condition. There was no cyanosis and no cardiac murmur was detected. The cardiac rate remained unaltered.

Electrocardiograms were taken on the second and third days. They confirmed the diagnosis, already suggested, of a congenital heart block. The first electrocardiogram showed an auricular rate of 167 per minute and a ventricular rate of 83 per minute. The second electrocardiogram gave an auricular rate of 150 per minute and a ventricular rate of 68 per minute. In both the electrocardiograms the $\mathbf{P}$ waves were upright in all leads, while the $\mathbf{P}-\mathbf{R}$ interval was variable. A skiagram which was taken at the age of two days showed a cardiac shadow extending further to the left than usual, and a narrow supracardiac shadow. A further skiagram which was taken a week later showed no change in the cardiac outline.

Unlike the findings in case 1 , the ventricular rate has not shown the same tendency to decrease as the infant grows. The observations made are given in the following table:

$\begin{array}{cc}\text { Age in days } & \text { Ventricular rate per minute } \\ 2 & 83 \\ 3 & 68 \\ 9 & 76 \\ 11 & 68 \\ 24 & 72 \\ 38 & 72 \\ 52 & 70 \\ 66 & 72 \\ 115 & 70\end{array}$

The most recent electrocardiogram taken at the age

FIG. 3.-Case 2. Electrocardiogram at age 2 days 


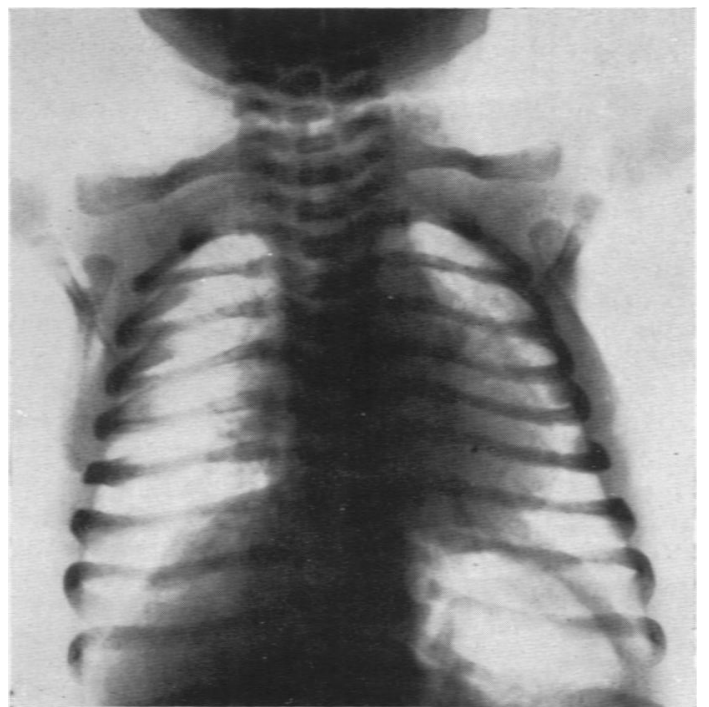

FIg. 4.-Case 2. Skiagram at age 2 days

of 8 weeks showed a persistence of the heart block. This breast-fed infant who is now sixteen weeks old has made satisfactory progress. The mother's electrocardiogram is normal.

\section{Commentary}

Nearly a hundred cases of congenital heart block have been recorded. Yater (1929) made an exhaustive survey of the literature to the end of 1928 . Hays (1934) reported three cases and gave a resumé of the literature. Of recent years cases have been recorded by Currie (1940), Geiger and Hines (1940), Stein and Uhr (1942), Leys (1943), Peel (1943), and Campbell (1943). Though uncommon the condition is probably not rare.

Etiology. The cause of congenital heart block has seldom been ascertained, for few of the published cases have come to autopsy. Of those which have, the necessary histological investigation has been made in only two cases. One of these, recorded by Yater (1929), showed a complete separation of the auriculo-ventricular node from the auriculoventricular bundle. The other, a case of $2: 1$ heart block recorded by Wilson and Grant (1925), showed a well developed auriculo-ventricular node, but the conducting fibres coming from it were interrupted and broken up by fibrous tissue only to reunite and divide into right and left branches lower down. None of this fibrous tissue appeared to be inflammatory in origin. In this connexion it is interesting to note the case of a five-year-old child with heart block, reported by Armstrong and Mönckeberg (1911). In this instance a small primary tumour was found localized in the auriculoventricular node.

An examination of the electrocardiograms of the two cases now recorded shows the presence of a normal ventricular complex. This is in keeping with the cases already published. It demonstrates that the lesion must be in the course of the main bundle of His above the bifurcation, and close to the interventricular septum. This occurrence has almost certainly given rise to the statement that congenital heart block is due to the presence of a septal defect. Such a premise is not supported by the histological investigations of Yater and of Wilson and Grant. In the latter case indeed, although the block was only partial, there was an entire absence of the interventricular septum. Moreover, a case of congenital heart block has been recorded by Witt (1934) in which no septal defect was found at autopsy. There was a coarctation of the aorta. It is most unfortunate that no histological investigation was made in this case. The rarity of heart block in cases of interventricular septal defect has been explained on the ground that the usual site of a septal defect is anterior to the pars membranacea whereas the bundle of His runs behind it. Though this is certainly true it is no proof that congenital heart block is due to a septal defect. The case recorded by Heubner (1938) in which the block disappeared when the infant reached the age of eleven months does not support the theory of septal defect. Neither does the case reported by Geiger and Hines. In this case the block appeared to begin at between seventeen and nineteen hours before delivery when the foetal heart rate dropped from 136 per minute to 64 per minute. These two cases suggest an entirely different etiology: Heubner's case suggests a recovery from an intrauterine illness, and the case of Geiger and Hines suggests the supervention of an intrauterine illness, or perhaps a haemorrhage, causing interference with the conducting power of the fibres. The two cases now reported throw no light on the etiology of the condition. It is clear that when the opportunity arises, extensive histological examination of the conducting fibres of the heart should be made in cases of congenital heart block.

Diagnosis. The diagnosis of congenital heart block is more often made after the child has reached the age of two years than before it. When the amount of ante-natal work which has been done during the past twenty years is considered this is somewhat surprising. Cases of congenital complete heart block should be suspected prior to birth and either confirmed or disproved in the neonatal period. The two cases now reported bring the total number of cases of complete heart block diagnosed ante-natally to seven. A summary of the main features of these cases is given in tabular form (table 1).

The need for the early diagnosis in cases of congenital complete heart block is forcibly illustrated by the incident reported by Stein and Uhr. In this instance, a child aged three years was being operated upon for acute mastoiditis when the anaesthetist directed the surgeon's attention to the slow pulse. Naturally, the possibility of an intradural absces 
TABLE 1

CONGENITAL COMPLETE HEART BLOCK. CASES DIAGNOSED ANTE-NATALLY

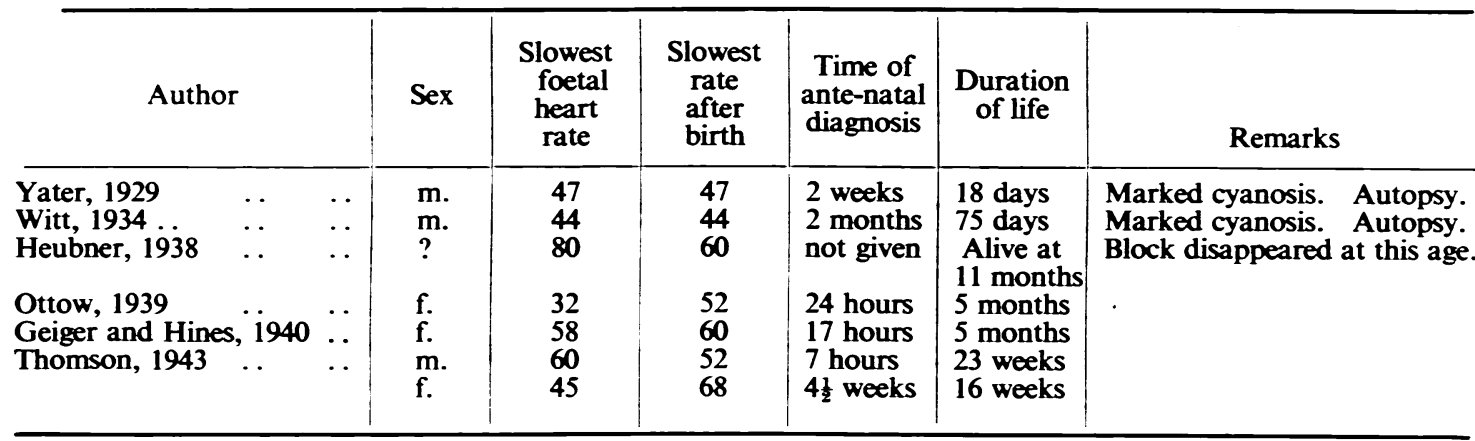

In all cases the diagnosis was confirmed by electrocardiogram.

was considered. Following upon a neurologist's negative report, the paediatrician to whom the case was then referred diagnosed a complete heart block.

In this case a low musical murmur was heard, probably due to a septal defect. A skiagram showed some right and left ventricular enlargement and the electrocardiogram confirmed the diagnosis. The auricular rate was 120 per minute and the ventricular rate 70 per minute.

Another instance in which a case of congenital heart block was overlooked is recorded by Campbell. He relates that a dental student who had a complete heart block contracted jaundice and was admitted to hospital. The slow pulse was remarked upon and the patient was demonstrated as having a bradycardia due to jaundice.

The possibility of Stokes-Adams seizure occurring in the case of heart block may explain some of those infantile or even ante-natal deaths in which at autopsy no cause for death can be found.

\section{Summary}

Two cases of congenital complete heart block, diagnosed ante-natally, are recorded. The need for histological examination of the heart in such cases is stressed. Attention is directed to the desirability of early diagnosis of congenital heart block.

\section{REFERENCES}

Armstrong, H., and Mönckeberg, J. G. (1911). Dtsch. Arch. klin. Med., 102, 143.

Campbell, M. (1943). Brit. Heart J., 5, 15.

Currie, G. M. (1940). Brit. med. J., 1, 769.

Geiger, C. J., and Hines, L. E. (1940). J. Amer. med. Ass., 115, 2272.

Hays, L. (1934). J. Pediat., 4, 380.

Heubner, D. (1938). Z. KreislForsch., 30, 600.

Leys, D. (1943). Brit. Heart J., 5, 8.

Ottow, B. (1939). Zbl. Ginäk., 63, 715.

Peel, A. A. F. (1943). Brit. Heart J., 5, 11.

Stein, W., and Uhr, J. S. (1942). Ibid., 4, 7.

Wilson, J. G., and Grant, R. T. (1925-6). Heart, 12, 295.

Witt, D. B. (1934). Amer. J. Dis. Child., 47, 380.

Yater, W. M. (1929). Ibid., 38, 112. 